\title{
Progresso científico em reprodução na primeira década do século XXI
}

\author{
Jairo Pereira Neves ${ }^{1}$, Karina Leite Miranda ${ }^{1}$, Rodrigo Dorneles Tortorella ${ }^{1}$ \\ ${ }^{1}$ Faculdade de Agronomia e Medicina Veterinária, Universidade de Brasília, Brasília-DF, Brasil.
}

RESUMO - O objetivo nesta revisão é mostrar os principais avanços científicos obtidos na área da reprodução animal e como estes podem afetar a eficiência reprodutiva e produtiva do rebanho bovino brasileiro. Com o conhecimento dos mecanismos envolvidos no controle da fisiologia reprodutiva, em níveis endócrino, celular e molecular, foi possível o desenvolvimento das biotécnicas reprodutivas, destacando-se a IATF, que tem sido utilizada em larga escala, por permitir a multiplicação de animais superiores geneticamente, aumentar a taxa de natalidade e ser eficaz no ajuste da estação reprodutiva notadamente em pecuária de corte. Outras biotécnicas, como a TE, PIVE, clonagem e transgênese, também são fundamentais no desenvolvimento de pesquisas de ciência básica, medicina e preservação animal. São apresentados também os principais fatores de manejo reprodutivo nutricional e sanitário que afetam a produtividade da pecuária leiteira. Contudo, o incentivo às pesquisas é fundamental para que estas biotécnicas sejam aprimoradas e continuem auxiliando o desenvolvimento da pecuária nacional.

Palavras-chave: avanços científicos, clonagem, fisiologia reprodutiva, inseminação artificial, transferência de embriões, PIVE

\section{Scientific progress in reproduction research during the first decade of XXI century}

\begin{abstract}
The aim of the review is to show the major scientific advances achieved in the animal reproduction area and how they can affect the productive and reproductive performance of cattle in Brazil. The knowledge about the mechanisms involved in the reproductive physiology control, in endocrine, cellular and molecular level allowed the development of reproductive biotechnologies. Among these the TAI has been used in large scale, with some advantages such as the multiplication of genetically superior animals, increasing on birth rate in addition to being an effective tool for adjusting the breeding season especially in beef cattle. Other biotechnologies such as ET, IVEP, cloning and transgenesis are also fundamental in the development of basic science, medicine and animal preservation researches. The main nutritional, reproductive and health management factors that affect the dairy cattle productivity are also presented. However, research incentive is essential to improve these biotechnologies, to continue helping the development of national livestock.
\end{abstract}

Key Words: artificial insemination, cloning, embryo transfer, IVEP, reproductive physiology, scientific advances

\section{Introdução}

A reprodução animal constitui-se num dos fatores de maior importância que afeta diretamente a eficiência e a rentabilidade dos sistemas produtivos. Segundo Moraes et al. (2008), a taxa de concepção nos ruminantes domésticos depende da manifestação do estro, que inclui todo um condicionamento fisiológico prévio de que a fêmea está apta a ovular e manter o desenvolvimento embrionário. Assim, a eficácia dos métodos reprodutivos é uma decorrência do percentual de fêmeas em estro e a taxa de fecundação em sistemas de sincronização e/ou indução da ovulação com inseminação após observação de estro ou em tempo fixo. No entanto, a eficiência reprodutiva ainda deixa a desejar. Como exemplo clássico, sabe-se que o intervalo de partos em uma fêmea bovina é de 12 meses, mas tem sido relatada uma variação de 14 a 21 meses fazendo com que o sistema produtivo tenha sua rentabilidade comprometida. Considera-se que estes índices não dependem unicamente do conhecimento científico, mas sim de outras questões como nutricionais, climáticas e mercadológicas. Mesmo assim, o Brasil é atualmente o maior produtor de carne bovina, o segundo de aves e o quarto de suínos.

O propósito desta revisão é apresentar alguns aspectos relacionados com a fisiologia da reprodução, inseminação artificial, eficiência reprodutiva no gado de 
leite, transferência de embriões, produção in vitro de embriões, clonagem e transgenia que mais evoluíram nos últimos anos.

\section{Fisiologia e endocrinologia da reprodução}

Os estudos relacionados à fisiologia e endocrinologia do ciclo estral da vaca foram intensificados a partir do advento da ultrassonografia, no qual se constatou que o padrão de crescimento folicular do ciclo estral se dá através de ondas, 2 a 3 (Ginther et al., 1989). Com isso, surgiu a possibilidade de correlacionar o aparecimento das estruturas ovarianas com os eventos endocrinológicos no ciclo estral. Técnicas recentes de ultrassonografia e biologia molecular permitiram um conhecimento mais preciso da fisiologia da dinâmica folicular que resultaram em diversos processos para o controle da ovulação, os quais permitiram o uso de biotecnologias como a inseminação artificial em tempo fixo (IATF), a transferência de embriões (TE) e a produção in vitro de embriões (PIVE) com índices mais elevados e resultados mais consistentes que permitem sua utilização em grande escala.

O ciclo estral na vaca é caracterizado por modificações cíclicas e morfológicas em seus órgãos reprodutivos e comportamento sexual, tendo duração de 18 a 24 dias, com média de 21 dias. O completo mecanismo da dominância folicular ainda não está totalmente esclarecido, porém sabe-se que vários fatores de crescimento estão envolvidos neste processo complexo e não somente as gonadotrofinas como o LH e FSH. O sistema IGF (fator de crescimento semelhante a insulina) é um dos fatores envolvidos nas modificações foliculares que ocorrem da fase de dominância. No folículo dominante, o crescimento em dimensão e o aumento da produção de estradiol são acompanhados por uma diminuição nos níveis de inibina, ativina e IGFBP (proteínas ligadoras do fator de crescimento semelhante à insulina) e aumento do IGF-1 livre (Fortune et al., 2001). O IGF-1 é capaz de estimular a proliferação e diferenciação das células da granulosa e o aparecimento de receptores de LH nestas células (Armstrong et al., 1996; Spicer \& Stewart, 1996).

Depois de estabelecida à dominância, se os níveis de progesterona $\left(\mathrm{P}_{4}\right)$ estiverem altos, inibindo assim a pulsatilidade do LH, o folículo dominante não irá ovular e entrará em atresia, iniciando uma nova onda folicular (Adams et al., 1992). Entretanto, quando os níveis de $\mathrm{P}_{4}$ estão baixos pela regressão luteal, o folículo dominante tem seu crescimento terminal, liberando maiores quantidades de $\mathrm{E}_{2}$ para circulação sanguínea. $\mathrm{O} \mathrm{E}_{2}$, através do feedback positivo, estimula os picos do hormônio liberador de gonadotrofinas $(\mathrm{GnRH})$ e consequentemente de LH, levando o folículo à ovulação (Ginther et al., 2001). Porém, é interessante ressaltar que menos de $0,1 \%$ dos folículos se desenvolverão a partir da fase pré-antral até a ovulação (Webb et al., 2007; Moraes et al., 2008;). Caso não ocorra fecundação a $\mathrm{PGF}_{2 \alpha}$ (Prostaglandina $\mathrm{F}_{2 \alpha}$ ) é liberada pelo útero levando à luteólise e um novo ciclo se iniciará. Ocorrendo a fecundação, o embrião sintetiza e secreta interferon $\tau$, entre os dias 15 a 26, que impedem a liberação de PGF $_{2 \alpha}$ pelo endométrio, mantendo o CL e a produção de $\mathrm{P}_{4}$ (Cunningham, 1999).

Como pôde ser observado, o sistema IGF faz parte do mecanismo de dominância e seleção, entretanto, este não é o único. Existem outros mecanismos envolvidos na foliculogênese, como o fator de crescimento fibroblástico (FGF) (Berisha et al., 2004; Buratini et al., 2007), o sistema renina-angiotensina (Ferreira et al., 2009; Portela et al., 2006) e a kisspeptina (Messager et al., 2005; Ohkura et al., 2008). Foram encontradas proteínas e/ou mRNAs dos FGF1, 2, 7, 8, 10 e 13 (Buratini et al., 2005, 2007; Berisha et al., 2004) além de receptores para FGF (FGFr) 2b, 3c e 4 nas células de folículos antrais (Buratini et al., 2005), demonstrando assim seu papel no desenvolvimento folicular.

Portella et al. (2006) concluíram que durante o crescimento folicular ocorre um aumento na expressão de receptores tipo II nas células da granulosa, enquanto que os receptores do tipo I aparentemente não variam. O completo mecanismo de ação da Ang-II no crescimento folicular ainda não está totalmente esclarecido. A kisspeptina assumiu um papel central na regulação do eixo hipotálamohipofisário-gonadal na medida em que foi descoberta a relação dos neurônios que a produzem com os neurônios do GnRH, estes possuindo receptores Kiss1r, no sistema nervoso central.

\section{Inseminação artificial (IA)}

De todas as biotécnicas utilizadas em reprodução animal, a IA é a mais antiga, mais simples e de maior impacto na produção animal. Esta técnica difundiu-se em todo o mundo como um instrumento eficaz e econômico para ser utilizado no melhoramento genético. Mesmo que simples e conhecida, requer uma série de requisitos, desde condições sanitárias e nutricionais dos animais, até laboratoriais. Além de programas eficientes de melhoramento para a seleção de reprodutores com as características superiores de interesse da produção e livres de doenças hereditárias (Reichenbach et al., 2008).

Um dos fatores limitantes dos índices reprodutivos e sucesso da IA é a detecção de estro, que é passível de falhas, principalmente nas fêmeas Bos indicus (Galina et al., 
1996), as quais apresentam estro de curta duração e muitas vezes durante a noite (Bó et al., 2003). Os programas hormonais são ferramentas que possibilitam a utilização da IA com a finalidade de concentrar a mão-de-obra utilizada na propriedade, sincronizar e induzir a ciclicidade dos animais, diminuir os efeitos ambientais e da amamentação, e consequentemente melhorar assim as taxas de prenhez. Os protocolos hormonais vêm sendo utilizados há algum tempo em vacas de corte durante o anestro pós-parto, porém as taxas de prenhez tem sido muito variáveis, 25-70\% (Martinez et a. 2002; Baruselli et al., 2004a; Kasimanickan et al., 2006; Borges et al., 2008; Siqueira et al., 2008), dependendo da interação entre meio ambiente e características individuais de cada rebanho.

Dentre os hormônios utilizados no tratamento hormonal em vacas no pós-parto estão os progestágenos, os derivados do 17- $\beta$ estradiol, o eCG, o FSHp, a PGF $2 \alpha$, e o GnRH. As associações feitas com estes hormônios visam aumentar a fertilidade do estro induzido e a precisão do momento da ovulação quando a IATF é utilizada. Foi através do conhecimento do desenvolvimento folicular que se descobriu que vacas Bos indicus e Bos taurus se comportavam de maneira diferente quanto ao número de ondas foliculares (Bó et al., 2003) tamanho folicular na divergência (Castilho et al., 2006; Sartorelli et al., 2005), tamanho de folículo ovulatório (Ginther et al., 1996; Sartori et al., 2001; Gimenes et al., 2008), tamanho do corpo lúteo e concentração de progesterona (Savio et al., 1988; Figueiredo et al., 1997).

Os progestágenos são de grande importância, visto que diminuem a ocorrência de ciclos curtos após a primeira ovulação e ajudam a restabelecer a ciclicidade (Perry et al., 2004; Sá Filho et al., 2009a,b). Os ciclos curtos devido à luteólise prematura são decorrentes de uma liberação precoce de $\mathrm{PGF}_{2 \alpha}$ por um número insuficiente de receptores de progesterona no endométrio (Zollers et al., 1993).

Quando os progestágenos são administrados de forma contínua, entre 5-9 dias, inibem a secreção de LH. A partir do momento em que a exposição a este hormônio é interrompida ocorre uma onda de LH capaz de induzir o crescimento do folículo pré-ovulatório, culminando com a ovulação. Contudo, a utilização destes progestágenos de forma indevida pode levar à formação de folículos persistentes. A partir desta dominância persistente, o desenvolvimento dos folículos torna-se desorganizado e quase sempre seus oócitos são inférteis (Fortune \& Rivera, 1999).

Com a finalidade de evitar a persistência folicular, derivados do estradiol 17- $\beta$ são utilizados em conjunto com os progestágenos, pois levam à regressão do folículo dominante e promovem um novo recrutamento folicular caracterizando uma nova onda folicular com grande potencial fertilizante (Bó et al., 2000). Os estrógenos utilizados com maior freqüência são o benzoato de estradiol (BE), cipionato do estradiol (CE) e o valerato de estradiol (VE). Estes hormônios levam à regressão de folículos LHdependentes por sua interação com a $\mathrm{P}_{4}$ e FSH dependentes por si só (Martinez et al., 2005), promovendo uma nova onda folicular após 4 e/ou 3 dias de sua aplicação (Bó et al., 2000).

Para realização da IATF é importante conhecer o momento da ovulação podendo ser usados hormônios indutores como, o GnRH e o BE. Após aplicação do GnRH, o pico de LH ocorre aproximadamente em 15 minutos e a IATF deve ser realizada em 16 horas (Lucy \& Stevenson, 1986). Já quando o BE é utilizado, o pico acontece entre 16 e 30 horas, sendo a IATF realizada após 30 horas (Mburu et al., 1998) quando este hormônio é aplicado um dia após a retirada da fonte de $\mathrm{P}_{4}$.

A capacidade de ovulação do folículo em um protocolo hormonal de IATF depende do tamanho folicular quando o indutor de ovulação é aplicado (Gimenes et al., 2008; Sartori et al., 2001), sendo esta uma das causas da grande variação de resposta aos protocolos hormonais. O eCG (Baruselli et al., 2004a, 2004b; Duffy et al., 2004), o desmame temporário (Geary et al., 2001; Siqueira et al., 2008) e o FSHp (Nascimento et al., 2007a,b; Santos et al., 2007b; Sá Filho et al., 2009a) são artifícios que podem ser utilizados para atenuar essa variação da resposta, pois estimulam o crescimento folicular final levando o folículo pré-ovulatório a um diâmetro compatível com a ovulação.

As técnicas de desmame visam minimizar os efeitos inibitórios da amamentação, visuais e táteis sobre a liberação de GnRH/LH no pós-parto (Stagg et al., 1998, Geary et al., 2001). O desmame precoce, separação permanente realizada aos 60-90 dias pós-parto, leva a bons resultados de prenhez ao fim da estação de monta (Gottschall et al., 2007; Loguércio, 2005), diminui o intervalo parto-concepção e aumenta a produção de carne (Almeida et al., 2002), porém depende de fatores ambientais e em, grande parte, da oferta alimentar.

O eCG é o hormônio produzido pelos cálices endometriais das éguas entre os dias 40-120 de gestação. Sua função primordial é estimular a manutenção do corpo lúteo primário e promover uma luteinização dos folículos secundários, formando assim corpos lúteos acessórios que ajudam a elevar a concentração de $\mathrm{P}_{4}$ até que a placenta seja a fonte principal da produção deste hormônio (Senger, 2003). Quando aplicado em fêmeas bovinas possui ação nos receptores $\mathrm{LH}$ e FSH estimulando a esteroidogênese e 
crescimento folicular (Duffy et al., 2004; Senger, 2003).

Quando o eCG é aplicado antes da retirada dos progestágenos e em doses baixas, o folículo dominante adquire maiores dimensões após suspensão do tratamento com progestágenos (Loguércio, 2005). Seu uso é necessário para animais com baixa condição corporal (CC <3), provavelmente devido à alta frequência de anestro encontrada nesta categoria (Baruselli et al., 2004b). Contudo algumas pesquisas recentes estudam a possibilidade da substituição do eCG por uma única aplicação de FSHp (Nascimento et al., 2007a,b; Santos et al., 2007a,b; Valentin et al., 2008).

$\mathrm{A}_{4}$ parece ter papel determinante no desenvolvimento embrionário, pois a concentração circulante deste hormônio durante o período de reconhecimento materno da prenhez é correlacionada com a taxa de crescimento embrionário, produção de INT - $\tau$ e taxa de prenhez (Stronge et al., 2005; McNeill et al., 2006). Estudos foram realizados na tentativa de aumentar as concentrações circulantes de $\mathrm{P}_{4}$ a partir da inserção de pessários vaginais em diferentes dias após inseminação (Mann et al., 2006; Carter et al., 2008; Beltman et al., 2009).

\section{Eficiência reprodutiva em gado de leite}

Propriedades com sistemas comerciais de produção de leite requerem uma especial atenção com as questões reprodutivas tais como manejo reprodutivo, controle do ciclo estral e infecções pós-parto com vistas à obtenção de índices reprodutivos sustentáveis. Elevados níveis de produção de leite associados com grande ingestão nutricional e correspondente atividade metabólica afetam a eficiência reprodutiva traduzindo-se pela ineficiente detecção do estro e redução das chances de prenhez após inseminação. Wiltbank et al. (2006) relataram que vacas Holandesas (Bos taurus) de alta produção apresentam estro de curta duração devido a uma menor concentração circulante de estradiol, decorrente do aumento do metabolismo hepático desse esteróide. Em consequência, os índices de prenhez ficam abaixo do desejável, situação esta não verificada no grupo das novilhas e das vacas fora da lactação (Moore \& Thatcher, 2006).

A reduzida fertilidade das vacas de leite é também devido a pouca viabilidade dos embriões traduzindo-se em morte embrionária precoce e tardia. Estas perdas estão fortemente associadas com o processo de lactação quando se compara com os índices obtidos com novilhas e vacas não lactantes. Rebanhos de alta produção devem ser mais bem observados quanto à condição nutritiva, sanitária e reprodutiva. Aumento da produção de leite é sempre acompanhado de um aumento da ingestão alimentar e atividade metabólica com repercussão negativa nas concentrações de estradiol e progesterona.

Outro fator que afeta as vacas de leite é o estresse calórico notadamente no dia do estro e nos que correspondem as primeiras divisões embrionárias resultando em perdas gestacionais. A utilização de algumas biotecnologias como a transferência de embriões poderá minimizar estas perdas. É também reconhecido que distúrbios de parto tais como distocias, retenção placentária e transtornos metabólicos são fatores que afetam a capacidade reprodutiva. Assim como as metrites clínicas e sub-clínicas que vão do período pós-parto até o período de nova concepção reduzem as chances para uma nova concepção. Para minimizar a incidência destas patologias é recomendável buscar um equilíbrio nutricional e sanitário antes, durante e após o parto para permitir uma boa condição imunológica. Neste contexto, também as mastites contribuem para que ocorram perdas reprodutivas.

A reposição de novilhas é uma necessidade constante nas produções leiteiras. Até um determinado tempo a única opção era a sexagem embrionária. Após 1987, Johnson implementou uma nova tecnologia fundamentada na separação de células espermáticas com base no conteúdo de DNA. Utilizando-se uma técnica de coloração fluorescente especial é possível realizar a separação dos espermatozóides X dos Y. No entanto há ainda dois gargalos que restringem o sucesso desta tecnologia. O primeiro é a baixa velocidade do processo e o outro é que cerca de $70 \%$ das células são eliminadas por limitação da etapa de identificação do equipamento e o segundo, refere-se a baixa concepção obtida após utilização do sêmen sexado, estimada em 35\%. Para minimizar estas dificuldades preconiza-se a utilização do sêmen sexado no primeiro serviço e o não sexado no caso de repetições de serviço. Por fim, trata-se de uma nova tecnologia que deverá cada vez mais ser incrementada até atingir um nível que permita ser utilizada com maior efetividade.

\section{Transferência de embriões (TE)}

A TE em bovinos continua sendo um dos métodos mais econômicos e práticos para o aumento das taxas reprodutivas de fêmeas de alto valor genético tanto em rebanhos de leite como de corte. Sua importância básica para a reprodução animal deve-se ao fato de que uma fêmea pode produzir um número de descendentes muito maior em relação a quantidade ao que poderia obter fisiologicamente por toda a sua vida reprodutiva. É uma biotecnologia importante por que acelera com maior precisão o processo de seleção animal, podendo ser empregada na obtenção de descendentes de fêmeas geneticamente superiores 
incapacitadas de ter uma prenhez a termo devido a distúrbios reprodutivos adquiridos. O desenvolvimento das técnicas de criopreservação de embriões foi fundamental para própria TE, possibilitando o transporte de embriões congelados entre rebanhos, evitando os custos e dificuldades do deslocamento de animais.

A TE representa maior segurança do ponto de vista epidemiológico para transmissão de enfermidades quando comparada ao trânsito de matrizes e reprodutores vivos. Porém, esse risco sanitário ainda existe e tem sido tema de muitas investigações científicas ao longo do tempo. O risco da introdução de doenças exóticas ou de cepas mais virulentas de doenças endêmicas por meio de gametas e embriões é uma preocupação constante, devido o grande potencial de risco não apenas no mercado de material genético, mas também de outros produtos de origem animal. Há mais de 20 anos trabalhos vêm mostrando o risco de transmissão de doenças infecto contagiosas pela TE (Bowen et al., 1983; Del Campo \& Tamayo, 1987; Wrathall, 1995; Stringfellow \& Givens, 2000; Le Tallec et al., 2001), entretanto, métodos de prevenção e controle de qualidade precisam ser aprimorados e padronizados, tanto para embriões e ovócitos, como para sêmen.

Produção in vitro de embriões bovinos (PIVE)

A PIVE vem sendo gradativamente incorporada nos programas de melhoramento animal como técnica de multiplicação, sendo que seu uso tem aumentando significativamente no país. De fato, o Brasil hoje ocupa uma posição de destaque no cenário mundial com consequente reconhecimento internacional, sendo responsável por quase $50 \%$ da produção mundial de embriões in vitro. Esta atividade concentrou-se, principalmente, em raças zebuínas de corte e seu sucesso se deve, entre outros fatores, à fisiologia reprodutiva dessas raças, que apresentam maior número de folículos disponíveis nos ovários em relação as taurinos. Portanto, é evidente o impacto dessa técnica na produção animal, que tem se destacado como o método de eleição para a multiplicação de animais de interesse econômico no Brasil (Viana \& Camargo, 2007).

Apesar dos avanços obtidos nos últimos anos na PIVE a sua utilização crescente em programas de melhoramento bovino, a proporção de embriões que atingem o estágio de blastocisto é, raramente, superior a 40\% e com índices de gestação em torno, também, de 40\%. Esses resultados se devem, provavelmente, às diferenças em várias características observadas entre os embriões produzidos in vitro e os produzidos in vivo.

\section{Clonagem e Transgênese}

A técnica de transferência nuclear ( $\mathrm{TN}$ ) está inserida no contexto das biotecnologias da reprodução animal e suas aplicações podem beneficiar, também, estudos na medicina, na conservação animal e na ciência básica, como a diferenciação celular, manipulação de genoma e herança citoplasmática. Além disso, contribuiu para o conhecimento de genes imprinted e fatores epigenéticos. Uma importante aplicação da TN está na associação com a tecnologia de modificação genética dos animais, os clones transgênicos. Os animais transgênicos podem ser utilizados para a produção de proteínas humanas recombinantes, xenotransplantes e estudos de doenças genéticas humanas. Já para o setor produtivo esta técnica atende programas de melhoramento genético com rápida multiplicação de animais com características desejáveis.

Os primeiros trabalhos de transferência nuclear utilizavam como fonte de núcleos blastômeros de embriões produzidos in vivo. Nos últimos anos, muitos trabalhos têm utilizado as células somáticas como doadoras de núcleo, o que permitiu um grande avanço da aplicação desta técnica. O avanço no uso de células somáticas para TN possibilitou caracterizar o fenótipo e o genótipo dos animais candidatos a serem clonados, especialmente aqueles que serão utilizados no programa da transgenia. Dentre as células somáticas que podem ser usadas no processo de transferência podem-se citar células da glândula mamária, fibroblastos fetais, células do cumulus, condrócitos, leucócitos e células tronco embrionárias.

O nascimento em março de 2001 da bezerra Vitória, primeiro animal produzido por transferência nuclear na America Latina, foi o primeiro passo para o estabelecimento da técnica de transferência nuclear de células somáticas na Embrapa Recursos Genéticos e Biotecnologia. Para esta bezerra utilizou-se células embrionárias e citoplasma de ovócitos pré-ativados, em que a enucleação foi realizada em telófase II, a qual normalmente é realizada em metáfase II (Souza et al., 2000). Estudos objetivando a utilização de fibroblastos fetais do animal adulto como doadores de núcleo e estudo sobre o efeito de diferentes passagens de células somáticas de orelha (Iguma et al., 2001) na técnica de TN resultaram no nascimento em 2003, no Centro experimental Sucupira, da bezerra Lenda. Essa foi produzida a partir de TN utilizando células da granulosa oriundas de um óvulo retirado do ovário de uma vaca holandesa morta (Iguma et al., 2003). Com objetivo de fazer uma TN de um animal clone foi produzida a Vitoriosa da Embrapa - primeiro clone do clone da América Latina. 
Freitas et al. (2003, 2007) testaram a produção de caprinos utilizando microinjeção de DNA codificado para humanos colônias de granulócitos com fator estimulante (G-CSF) em pró-nucleos de embriões caprinos os quais foram transferidos para receptoras em condições tropicais brasileiras. Este experimento estabeleceu os procedimentos básicos de sincronização e superovulação com o propósito de obtenção de pró-núcleos embrionários. Foi o primeiro relato no Brasil do nascimento de descendentes após microinjeção de prónúcleos embrionários. A construção do DNA contendo o gene do hG-CSF franqueado pelos genes caprinos e bovino da alfas1-caseína, foi injetada em 129 embriões. Os embriões microinjetados foram transferidos para 27 receptoras que responderam ao tratamento. Dez receptoras ficaram gestantes e 12 crias foram produzidas. Um macho transgênico fundador foi identificado no grupo de crias nascidas. Este foi o primeiro relato do nascimento de um caprino transgênico na America Latina.

\section{Conclusões}

O notável progresso ocorrido nos últimos anos gerou grande impacto na comunidade acadêmica com importantes reflexos no setor produtivo. Para a grande maioria da comunidade estes avanços geram conhecimentos como também viabilizam o desenvolvimento de novas tecnologias. Para uma minoria podem ser vistas como desnecessárias e de baixa confiabilidade. O que se deve ressaltar é a necessidade de um perfeito conhecimento mediante avaliação técnica das situações peculiares de cada rebanho para verificação da aplicabilidade ou não destas biotecnologias e sua sustentabilidade.

\section{Referências}

ADAMS, G.P.; MATTERI, R.L.; KASTELIC, J.P. et al. Association between surges of follicle stimulating hormone and the emergence of follicular waves in heifers. Journal of Reproduction and Fertility, v.94, p.177-188, 1992.

ALMEIDA, L.S.P.; LOBATO, J.F.P.; SCHENKEL, F.S. Data de desmame e desempenho reprodutivo de vacas de corte. Revista Brasileira de Zootecnia, v.31, p.1223-1229, 2002.

ARMSTRONG, D.T.; XIA, P.; GANNES, DE D. et al. Differential effects of insulin-like growth factor-I and follicle stimulating hormone on proliferation and differentiation of bovine cumulus cells and granulosa cells. Biology of Reproduction, v.54, p.331-338, 1996.

BARUSELLI, P.S.; REIS, E.L.; MARQUES, M.O. et al. The use of homonal treatments to improve reproductive performance of anestrous beef cattle in tropical climates. Animal reproduction Science, v.82-83, p.479-486, $2004 \mathrm{a}$.

BARUSELLI, P.S.; MADUREIRA, E.H.; MARQUES, M.O. et al. Efeito do tratamento com eCG na taxa de concepção de vacas Nelore com diferentes escores de condição corporal inseminadas em tempo fixo (Análise retrospectiva). In: REUNIÃO ANUAL
DA SOCIEDADE BRASILEIRA DE TECNOLOGIA DE EMBRIÕES, 32., 2004, Barra Bonita. Anais... Barra Bonita: SBTE, 2004b. p.228 (supl.).

BELTMAN, M.E.; LONERGAN, P.; DISKIN, M.G. et al. Effect of progesterone supplementation in the first week post conception on embryo survival in beef heifers. Theriogenology, 2009, doi:10.1016/j.theriogenology.2008.12.014

BERISHA, B.; SINOWATZ, F.; SCHAMS, D. Expression and localization of fibroblastic growth factor (TGF) family members during the final growth of bovine ovarian follicles. Molecular Reproduction and Development, v.67, p.162171, 2004.

BÓ, G.A.; BARUSELli, P.S.; MARTINEZ, M.F. Pattern and manipulation of follicular development in Bos indicus. Animal Reproduction Science, v.78, p.307-326, 2003.

BÓ, G.A.; BERGFELT, D.R.; BROGLIATTI, G.M. et al. Local versus systemic effects of exogenous estradiol-17[beta] on ovarian follicular dynamics in heifers with progestogen implants. Animal Reproduction Science, v.59, p.141-157, 2000.

BORGES, L.F.K.; FERREIRA, R.; SIQUEIRA, L.C. et al. Sistema para inseminação artificial sem observação de estro em vacas de corte amamentando. Ciência Rural, v.39, n.2, p.496-501, 2008.

BOWEN, R.A.; HOWARD, T.H.; ELSDEN, R.P. et al. Embryo transfer from cattle infected with bluetongue virus. American Journal of Veterinary Research, v.44, p.1625-1628, 1983.

BURATINI JR., J.; PINTO, M.G.L.; CASTILHO, A.C. et al. Expression and function of fibroblast growth factor 10 and its receptor, fibroblast growth factor receptor $2 \mathrm{~B}$, in bovine follicles. Biology of Reproduction, v.77, p.743-750, 2007.

BURATINI JR., J.; TEIXEIRA, A.B.; COSTA, I.B. et al. Expression of fibroblast growth factor-8 and regulation of cognate receptors, fibroblast growth factor receptor $-3 \mathrm{c}$ and $-4 \mathrm{c}$, in bovine antral follicles. Reproduction, v.130, p.343-350, 2005.

CARTER, F.; FORDE, N.; DUFFY, P. et al. Effect of increasing progesterone concentration from Day 3 of pregnancy on subsequent embryo survival and development in beef heifers. Reproduction, Fertility and Development, v.20, p.368375, 208.

CASTILHO, C.; GARCIA, J.M.; RENESTO, A. et al. Follicular dynamics and plasma FSH and progesterone concentrations during follicular deviation in the first post-ovulatory wave in Nelore (Bos indicus) heifers. Animal Reproduction Science, v.98, p.189-96, 2006.

CUNningham, J.G. Tratado de fisiologia veterinária. 2.ed. Rio de Janeiro: Guanabara Koogan, 1999, p.353-375.

Del CAMPO, M.R.; TAMAYO, R. Embryos transfer from brucellosis-positive donors: a field trial. Theriogenology, v.27, p.221, 1987.

DUFFY, P.; CROWE, M.A.; AUSTIN, E.J. et al. The effect of eCG or estradiol at or after norgestomet removal on follicular dynamics, estrus and ovulation in early post-partum beef cows nursing calves. Theriogenology, v.61, p.725-734, 2004.

FERREIRA, R.; GASPERIN, B.G.; BOHRER, R.C. et al. The role of angiotensin II in bovine follicular growth. Biology of Reproduction, v.78, p.222-222, 2009.

FIGUEIREDO, R.A.; BARROS, C.M.; PINHEIRO O.L. et al. Ovarian follicular dynamics in Nelore breed cattle. Theriogenology, v.47, p.1489-1505, 1997.

FORTUNE, J.E. et al. Differentiation of dominant versus subordinate follicles in cattle. Biology of Reproduction, v.65, p.648-654, 2001.

FORTUNE, J.E.; RIVERA, G.M. Folículo dominante persistente em bovinos: aspectos básicos e aplicados. Arquivos da Faculdade de Veterinária UFRGS, v.27, p.22-34, 1999.

FREITAS, V.J.F.; SEROVA, I.A.; ANDREEVA, L.E. et al. Birth of normal after microinjection of pronuclear embryos in a transgenic goat (Capra hircus) production program in Brazil. Genetics and Molecular Research, v.2, n.2, p.200-205, 2003. 
FREITAS, V.J.F., SEROVA, I.A., ANDREEVA,L.E. et al. Production of transgenic goat (Capra hircus) with human Granulocyte Colony Stimulating Factor (hG-CSF) gene in Brazil. Academia Brasileira de Ciências, v.79, p.585-592, 2007.

GALINA, C.S.; ORIHUELA, A.; RUBIO, I. Behavioural trends affecting oestrus detection in Zebu cattle. Animal Reproduction Science, v.42, p.465-470, 1996.

GEARY, T.W.; WHITTIER, J.C.; HALLFORD, D.M. et al. Calf removal improves conception rates to the Ovsynch and COSynch protocols. Journal of Animal Science, v.79, p.1-4, 2001.

GIMENES, L.U.; SÁ FILHO, M.F.; CARVALHO, N.A.T. et al. Follicle deviation and ovulatory capacity in Bos indicus capacity.Theriogenology, v.69, p.852-858, 2008.

GINTHER, O.J.; KNOPF, L.; KASTELIC, J.P. Temporal associations among ovarian events in cattle during oestrous cycles with two and three follicular waves. Journal of Reproduction and Fertility, v.87, p.223-230, 1989.

GINTHER, O.J.; WILTBANK, M.C.; FRICKE, P.M. et al. Selection of the dominant follicle in cattle. Biology of Reproduction, v.55, p.1187-1194, 1996.

GINTHER, O.J.; BERGFELT, D.R.; BEG, M.A. et al. Follicle selection in cattle: role of luteinizing hormone. Biology of Reproduction, v.64, p.197-205, 2001.

GOTTSCHALL, C.S.; FERREIRA, E.T.; CANELLAS, L. et al. The reproductive performance of beef cows of different ages with calves weaned at three or seven months. Animal Reproduction, v.4, p.42-45, 2007.

IGUMA, L.T.; SOUZA, R.B.; RUMPF, R. Efeito das diferentes passagens no cultivo in vitro de células somáticas quando utilizadas na transferência nuclear em bovinos. In: ENCONTRO DO TALENTO ESTUDANTIL, 6., 2001, s.l. Anais... s.l.: 2001.

IGUMA, L.T.; SOUZA, R.B.; CARRIJO JR., A. et al. Clonagem e reclonagem de animais de conservação a partir de fibroblastos da orelha de bovinos adultos. Acta Scientiae Veterinariae, v.31 (Supl.) 2003.

KASIMANICKAM, R.; COLLINS, J.C.; WUENSCHELL, J. et al. Effect of timing of prostaglandin administration, controlled internal drug release removal and gonadotrophin releasing hormone administration on pregnancy rate in fixed-time AI protocols in crossbred Angus cows. Theriogenology, v.66, p.166-172, 2006.

Le TALLEC, B.; PONSART, C.; MARQUANT-Le GUIENNE, B. ; GUÉRIN, B. Risks of transmissible diseases in relation to embryo transfer. Reproduction Nutrition Development, v.41, p.439-450, 2001.

LOGUÉRCIO, R.S. Regulação de receptores esteróides e dinâmica folicular em um sistema de indução hormonal pós-parto em vacas de corte. 2005. 80f. Tese (Doutorado em Medicina Veterinária), Curso de Pós-Graduação em Medicina Veterinária, Universidade Federal de Santa Maria, Santa Maria, 2005.

LUCY, M.C.; STEVENSON, J.S. Gonadotrophin-releasing hormone at estrus: luteinizing hormone, estradiol, and progesterone during the periestrual and postinsemination periods in dairy cattle. Biology of Reproduction, v.35, p.300-311, 1986.

MANN, G.E.; FRAY, M.D.; LAMMING, G.E. Effects of time of progesterone supplementation on embryo development and interferon-s production in the cow. The Veterinary Journal, v.171, p.500-503, 2006.

MARTINEZ, M.F.; KASTELIC, J.P.; ADAMS, G.P. et al. The use of progestins in regimens for fixed-time artificial insemination in beef cattle. Theriogenology, v.57, p.1049-1059, 2002.

MARTINEZ, M.F.; KASTELIC, J.P.; BO, G.A. et al. Effects of oestradiol and some of its esters on gonadotrophin release and ovarian follicular dynamics in CIDR-treated beef cattle. Animal Reproduction Science, v.86, p.37-52, 2005.

MBURU, J.N.; EINARSSON, S.; KINDAHL, H. et al. Effects of post-ovulatory food deprivation on oviductal sperm concentration, embryo development and hormonal profiles in the pig. Animal Reproduction Science, v.52, p.221-234, 1998.

McNEILL, R.E.; DISKIN, M.G.; SREENAN, J.M. et al. Associations between milk progesterone concentration on different days and with embryo survival during the early luteal phase in dairy cows. Theriogenology, v.65, p.1435-1441, 2006.

MESSAGER, S.; CHATZIDAKI, E.E.; MA, D. et al. Kisspeptin directly stimulates gonadotrophin releasing hormone release via G protein-coupled receptor 54. Proceedings of the National Academy of Science, v.102, p.1761-1766, 2005.

MOORE, K.; THATCHER, W.W. Major advances associated with reproduction in dairy cattle. Journal of Dairy Science, v.89, p.1254-1266, 2006.

MORAES, J.C.F.; DE SOUZA, C.J.H.; GONÇALVES, P.B.D. Controle do estro e ovulação em ruminantes. In: GONÇALVES, P.B.D. FIGUEIREDO, J.R.; FREITAS, V.J.F. (Eds.) Biotécnicas aplicadas à reprodução animal. 2.ed. São Paulo: Roca, 2008. p.33-56.

NASCIMENTO, V.A.; TORRES, C.A.A.; DIAS, M. et al. Taxas de prenhez com o uso do FSH-p na sincronização da ovulação em vacas da raça Nelore. In: REUNIÃO ANUAL DA SOCIEDADE BRASILEIRA DE TECNOLOGIA DE EMBRIÕES, 35., 2007, Salvador. Anais... Salvador: SBTE, 2007a. p.1135. (supl. 3).

NASCIMENTO, V.A.; TORRES, C.A.A.; DIAS, M. et al. Dinâmica folicular na sincronização de ovulação associado à administração de FSH-p em vacas da raça Nelore. In: REUNIÃO ANUAL DA SOCIEDADE BRASILEIRA DE TECNOLOGIA DE EMBRIÕES, 35., 2007, Salvador. Anais... Salvador: SBTE, 2007b. p.1134. (supl. 3).

OHKURA, S.; UENOYAMA, Y.; YAMADA, S. et al. Physiological role of metastin/kisspeptin in regulating gonadotropin-releasing hormone (GnRH) secretion in female rats. Peptides, 2008. (in press).

OLIVEIRA R.R.; CARVALHO D.M.; LISAUSKAS S. et al. Effectiveness of liposomes to transfect livestock fibroblasts. Genetic Molecular Research, v.4, n.2, p.185-96, 2005.

PERRY, G.A.; SMITH, M.F.; GEARY, T.W. Ability of intravaginal progesterone inserts and melengestrol acetate to induce estrous cycle in postpartum beef cows. Journal of Animal Science, v.82, p.695-704, 2004.

PORTELA, V.V.; GONÇALVES, P.B.D.; FREITAS, V.J.F. et al. A novel role for angiotensin-II in the regulation of proteasenexin-I expression and secretion in bovine follicles. In: ANNUAL MEETING OF THE SOCIETY FOR THE STUDY OF REPRODUCTION, 39., 2006, s.l. Proceedings... s.l.: 2006. (Abstract 452).

REICHENBACH, H.D.; MORAES, J.C.F.; NEVES, J.P. Tecnologia de sêmen e inseminação artificial em bovinos. In: GONÇALVES, P.B.D.; FIGUEIREDO, J.R.; FREITAS, V.J.F. (Eds.) Biotécnicas aplicadas à reprodução animal. 2.ed. São Paulo, Roca: 2008. p.57-82.

SÁ FILHO, O.G.; MENEGHETTI, M.; PERES, R.F.G. et al. Fixedtime artificial insemination with estradiol and progesterone for Bos indicus cows. II: Strategies and factors affecting fertility. Theriogenology, v.72, p.210-218, 2009a.

SÁ FILHO, O.G.; THATCHER, W.W.; VASCONCELOS, J.L.M. Effect of progesterone and/or estradiol treatments prior to induction of ovulation on subsequent luteal lifespan in anestrous Nelore cows. Animal Reproduction Science, v.112, p.95106, 2009b.

SANTOS, I.C.C.; MARTINS, C.M.; BARUSELLI, P.S. et al. Estudo da dinâmica folicular de vacas Nelore (Bos indicus) em anestro sincronizadas com protocolo IATF, utilizando Folltropin (FSHp) como indutor de crescimento folicular. In: REUNIÃO ANUAL DA SOCIEDADE BRASILEIRA DE TECNOLOGIA DE EMBRIÕES, 35., 2007, Salvador. Anais... Salvador: SBTE, 2007a. p.1152. (supl. 3).

SANTOS, I.C.C.; MARTINS, C.M.; VALENTIN, R. et al. Taxa de prenhez a IATF de vacas zebuínas em anestro tratadas com 
dose única de FSHp (Folltropin $\left.{ }^{\circledR}\right)$. In: REUNIÃO ANUAL DA SOCIEDADE BRASILEIRA DE TECNOLOGIA DE EMBRIÕES, 35., 2007, Salvador. Anais... Salvador: SBTE, 2007b. p.1151. (supl. 3).

SARTORELLI, E.S.; CARVALHO, L.M.; BERGFELT, D.R. et al. Morphological characterization of follicle deviation in Nelore (Bos indicus) heifers and cows. Theriogenology, v.63, p.23822394, 2005.

SARTORI, R.; FRICKE, P.M.; FERREIRA, J.C.P. et al. Follicular deviation and acquisition of ovulatory capacity in bovine follicles. Biology of Reproduction, v.65, p.1403-1409, 2001.

SAVIO, J.D.; KEENAN, L.; BOLAND, M.P. et al. Pattern of growth of dominant follicles during the estrous cycle of heifers. Journal of Reproduction of Fertility, v.83, p.663-671, 1988.

SENGER, P.L. Pathways to pregnancy and parturition. 2.ed. Washington: Current Conceptions, 2003. 314p.

SIQUEIRA, L.C.; OLIVEIRA, J.F.C.; LOGUÉRCIO, R.S. et al. Sistemas de inseminação artificial em dois dias com observação de estro ou em tempo fixo para vacas de corte amamentando. Ciência Rural, v.38, n.2, p.411-415, 2008.

SPICER, L.J.; STEWART, R.E. Interactions among basic fibroblastic growth factor, epidermal growth factor, insulin, and insulin-like growth factor-I (IGF-I) on cell numbers and steroidogenesis of bovine thecal cells: role of IGF-I receptors. Biology of Reproduction, v.54, p.255-263, 1996.

SOUZA, R.V.; IGUMA, L.T.; NASCIMENTO, N. et al. Clonagem de embriões bovinos congelados utilizando citoplasmas receptores pré-ativados. Arquivos Faculdade de Veterinária UFRGS，v.28，n.1, 2000 (supl.).

STAGG, K.; SPICER, L.J.; SREENAN, J.M. et al. Effect of calf isolation on follicular wave dynamics, gonadotrophin and metabolic hormone changes, and interval to first ovulation in beef cows fed either of two energy levels postpartum. Biology of Reproduction, v.59, p.777-783, 1998.

STRINGFELLOW, D.A.; GIVENS, M.D. Infectious agents in bovine embryo production: harzards and solutions. Theriogenology, v.53, p.85-94, 2000.

STRONGE, A.J.; SREENAN, J.M.; DISKIN, M.G. et al. Postinsemination milk progesterone concentration and embryo survival in dairy cows. Theriogenology, v.64, p.1212-1224, 2005.

VALENTIN, R.; MARQUES, M.O.; CREPALDI, G.A. et al. Efeito do tratamento com FSH na retirada do dispositivo intravaginal de progesterona sobre a taxa de prenhez de primíparas Nelore inseminadas em tempo fixo. In: REUNIÃO ANUAL DA SOCIEDADE BRASILEIRA DE TECNOLOGIA DE EMBRIÕES, 36., 2008, Guarujá. Anais... Guarujá: SBTE, 2008. p.597. (supl. 2).

VIANA, J.H.M.; CAMARGO, L.S.A. A produção de embriões bovinos no Brasil: uma nova realidade. Acta Scientiae Veterinariae, v.3, p.s915-s924, 2007 (supl.3).

WEBB, R.; GARNSWORTHY, P.C.; CAMPBELL, B.K. et al. Intraovarian regulation of follicular development and oocyte competence in farm animals. Theriogenology, v.68, p.S22S29, 2007.

WILTBANK, M.C.; LOPEZ, H.; SARTORI, R. et al. Changes in reproductive physiology of lactating dairy cows due to elevated steroid metabolism. Theriogenology, v.65, p.17-29, 2006.

WRATHALL, A.E. Embryo transfer and disease transmission in livestock: a review of recent research. Theriogenology, v.43, p.81-88, 1995.

ZOLLERS, W.G.; GARVERICK, H.A.; SMITH M.F. et al. Concentrations of progesterone and oxytocin receptors in endometrium of postpartum cows expected to have a short or normal oestrous cycle. Reproduction, v.97, p.329-337, 1993. 